\title{
Autoinhibition of Oxidation by Oxygen
}

\author{
Michael M. Silaev
}

Department of Chemistry, Lomonosov Moscow State University, Vorob'evy Gory, Moscow 119991, Russia

\begin{abstract}
New reaction scheme is suggested for the initiated nonbranched-chain addition of free radicals to the multiple bond of the molecular oxygen. The scheme includes the reaction competing with chain propagation reactions through a reactive free radical. The chain evolution stage in this scheme involves a few of free radicals, one of which (tetraoxyl) is relatively low-reactive and inhibits the chain process by shortening of the kinetic chain length. Based on the proposed scheme rate equations (containing one to three parameters to be determined directly) are deduced using quasi-steadystate treatment. The kinetic description with use the obtained rate equations is applied to the $\mathrm{y}$-induced nonbranchedchain processes of the free-radical oxidation of liquid o-xylene at $373 \mathrm{~K}$ and hydrogen dissolved in water containing different amounts of oxygen at $296 \mathrm{~K}$. In these processes the oxygen with the increase of its concentration begins to act as an oxidation autoingibitor (or an antioxidant), and the rate of peroxide formation as a function of the dissolved oxygen concentration has a maximum. The energetics of the key radical-molecule reactions is considered.
\end{abstract}

Keywords: Competition, low-reactive radical, autoinhibitor, thermochemical data, energy, hydrogen.

\section{INTRODUCTION}

The kinetics of inhibition for nonbranched-chain processes of saturated free-radical addition to the $\mathrm{C}=\mathrm{C}$ and $\mathrm{C}=\mathrm{O}$ double bonds of alkene and formaldehyde molecules, respectively, by low-reactive free radicals that can experience delocalization of the unpaired $p$ electron was first considered in [1]. In these processes a low-reactive free radical is formed in the reaction competing with chain propagation reactions through a reactive free radical. In the present work the kinetics of inhibition by low-reactive tetraoxyl free radicals is considered for nonbranched-chain processes of the addition of a free radical or an atom to one of the two multiply bonded atoms of the oxygen molecule yielding a peroxyl free radical and thus initiating oxidation, which is the basic process of chemical evolution. The peroxyl free radical then abstracts the most labile atom from a molecule of the compound being oxidized or decomposes to turn into a molecule of an oxidation product. The only reaction that can compete with these two reactions at the chain evolution stage is the addition of the peroxyl radical to the oxygen molecule (provided that the oxygen concentration is sufficiently high). This reaction yields the secondary tetraoxyl 1:2 adduct radical, which is the heaviest and the largest among the reactants. It is less reactive than the primary peroxyl 1:1 adduct radical and, as a consequence, does not participate in further chain propagation. At moderate temperatures, the reaction proceeds via a nonbranched-chain mechanism.

*Address correspondence to this author at the Department of Chemistry, Lomonosov Moscow State University, Vorob'evy Gory, Moscow 119991, Russia; Tel: +7(495)939 4870; Fax: +7(495)932 8846;

E-mail: mmsilaev@rc.chem.msu.ru
The aim of this study was the mathematical simulation of oxidation process autoinhibited by oxygen, when the dependence of the peroxide formation rate on the dissolved oxygen concentration has a maximum. The simulation was based on experimental data reported in the literature for $\mathrm{Y}$ radiation-induced addition reaction of hydrocarbon free radical $\mathrm{R}^{\cdot}$ (or hydrogen atom) to the molecular oxygen for which the initiation rate $V_{1}$ is known (taking into account that $V=G P$ and $V_{1}=\varepsilon G\left(\mathrm{R}^{\circ}\right) P$, where $P$ is the dose rate, $\varepsilon$ is the electron fraction of the solvent $\mathrm{RH}$ in the binary hydrocarbon-dioxygen system [2], and $G\left(R^{*}\right)$ is the initial yield of the chain-carrier free radical $R^{\circ}$ initiation yield $[3,4])$.

\section{ADDITION OF HYDROCARBON FREE RADICALS}

Usually, the convex curve of the hydrocarbon autooxidation rate as a function of the partial pressure of molecular oxygen ascends up to some limit and then flattens out [5]. When this is the case, the oxidation kinetics is satisfactorily describable in terms of the conventional reaction scheme [5-10], which involves two types of free radicals. These are the hydrocarbon radical $\mathrm{R}^{*}$ (addend radical) and the addition product $\mathrm{RO}_{2}^{*}$ (1:1 adduct radical). However, the existing mechanisms are inapplicable to the cases in which the rate of initiated oxidation as a function of the oxygen concentration has a maximum (Figures 1, 2) [11, 12]. Such dependences can be described in terms of the competition kinetics of free-radical chain addition, whose reaction scheme involves not only the above two types of free radicals, but also an $\mathrm{RO}_{4}^{-}$radical (1:2 adduct) inhibiting the chain process $[13,14]$. 
Chain initiation

1. $\mathrm{I} \stackrel{2 k_{1}}{\longrightarrow} 2 \mathrm{R}_{0}^{\bullet}$;

1a. $\mathrm{R}_{0}^{\bullet}+\mathrm{RH} \stackrel{k_{1 a}}{\longrightarrow} \mathrm{R}_{0} \mathrm{H}+\mathrm{R}^{\bullet}$.

Chain propagation

2. $\mathrm{R}^{\bullet}+\mathrm{O}_{2} \stackrel{k_{2}}{\longrightarrow} \mathrm{RO}_{2}^{*}$;

3. $\mathrm{RO}_{2}^{\circ}+\mathrm{RH} \stackrel{\mathrm{k}_{3}}{\longrightarrow} \mathrm{RO}_{2} \mathrm{H}+\mathrm{R}^{\cdot}$

(or $\mathrm{ROH}+\mathrm{RO}^{\circ}$ );

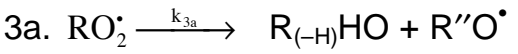

(or $\mathrm{R}_{(-2 \mathrm{H})} \mathrm{HO}+{ }^{\circ} \mathrm{OH}$ );

3b. $\mathrm{R}^{\prime \prime} \mathrm{O}^{\circ}\left(\mathrm{RO} \mathrm{O}^{\circ}\right)+\mathrm{RH} \stackrel{\mathrm{k}_{3 b}}{\longrightarrow} \mathrm{R}^{\prime \prime} \mathrm{OH}(\mathrm{ROH})+\mathrm{R}^{\cdot}$

$$
\text { (or }{ }^{\circ} \mathrm{OH}+\mathrm{RH} \stackrel{\mathrm{k}_{3 b}}{\longrightarrow} \mathrm{H}_{2} \mathrm{O}+\mathrm{R}^{\circ} \text { ). }
$$

Inhibition

4. $\mathrm{RO}_{2}^{\circ}+\mathrm{O}_{2} \stackrel{\mathrm{k}_{4}}{\longrightarrow} \mathrm{RO}_{4}^{\bullet}$.

Chain termination

5. $2 \mathrm{R} \cdot \stackrel{2 k_{5}}{\longrightarrow} \mathrm{RR}$

$$
\text { (or } \mathrm{R}_{(-2 \mathrm{H})} \mathrm{H}+\mathrm{RH} \text { ); }
$$

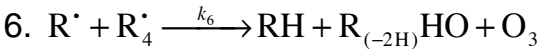

$$
\begin{array}{cl}
\text { (or: } & \mathrm{R}_{(-2 \mathrm{H})} \mathrm{H}+\mathrm{R}_{(-2 \mathrm{H})} \mathrm{HO}+\mathrm{H}_{2} \mathrm{O}+\mathrm{O}_{2} \\
& \mathrm{ROH}+\mathrm{R}_{(-2 \mathrm{H})} \mathrm{HO}+\mathrm{O}_{2} \\
& \mathrm{ROR}+\mathrm{O}_{3} \\
& \left.\mathrm{RO}_{2} \mathrm{R}+\mathrm{O}_{2}\right)
\end{array}
$$

7. $2 \mathrm{RO}_{4}^{\bullet} \stackrel{2 k_{7}}{\longrightarrow} \mathrm{R}_{(-2 \mathrm{H})} \mathrm{H}+\mathrm{R}_{(-2 \mathrm{H})} \mathrm{HO}+\mathrm{H}_{2} \mathrm{O}+3 \mathrm{O}_{2}$ or $2 \mathrm{O}_{3}$

$$
\begin{array}{ll}
\text { (or: } & \mathrm{ROH}+\mathrm{R}_{(-2 \mathrm{H})} \mathrm{HO}+3 \mathrm{O}_{2} \text { or } 2 \mathrm{O}_{3} \\
& 2 \mathrm{R}_{(-2 \mathrm{H})} \mathrm{HO}+\mathrm{H}_{2} \mathrm{O}_{2}+2 \mathrm{O}_{2} \\
& 2 \mathrm{R}_{(-2 \mathrm{H})} \mathrm{HO}+\mathrm{H}_{2} \mathrm{O}+\mathrm{O}_{3}+\mathrm{O}_{2} \\
& \left.\mathrm{RO}_{2} \mathrm{R}+3 \mathrm{O}_{2} \text { or } 2 \mathrm{O}_{3}\right)
\end{array}
$$

Scheme 1: Nonbranched-chain oxidation of hydrocarbons ${ }^{1}$.

\footnotetext{
${ }^{1}$ The only difference between the kinetic model of oxidation and the kinetic model of the chain addition of 1-hydroxyalkyl radicals to the free (unsolvated) form of formaldehyde in nonmethanolic alcohol-formaldehyde systems $[1,15]$ is that in the former does not include the formation of the molecular 1:1 adduct via reaction 4
}

The decomposition of the initiator I in reaction 1 yields a reactive $R_{0}^{*}$ radical, which turns into the ultimate product $\mathrm{R}_{0} \mathrm{H}$ via reaction 1a, generating an alkyl radical $\mathrm{R}^{\circ}$, which participates in chain propagation. In reaction 2 , the addition of the free radical $R^{\circ}$ to the oxygen molecule yields a reactive alkylperoxyl 1:1 adduct radical $\mathrm{RO}_{2}^{\circ}$ [10], which possesses increased energy owing to the energy released upon the conversion of the $\mathrm{O}=\mathrm{O}$ bond into the ordinary bond $\mathrm{RO}^{-} \mathrm{O}^{\circ}$ (for addition in the gas phase under standard conditions, this energy is $115-130 \mathrm{~kJ} \mathrm{~mol}^{-1}$ for $\mathrm{C}_{1}-\mathrm{C}_{4}$ alkyl radicals $[6,16,17]$ and $73 \mathrm{~kJ} \mathrm{~mol}^{-1}$ for the allyl radical [17]). Because of this, the adduct radical can decompose (reaction $3 a$ ) or react with some neighbor molecule (reaction 3 or 4 ) on the spot, without diffusing in the solution and, accordingly, without entering into any chain termination reaction. In reaction 3 , the interaction between the radical adduct $\mathrm{RO}_{2}^{\circ}$ and the hydrocarbon molecule $\mathrm{RH}$ yields, via a chain mechanism, the alkyl hydroperoxide $\mathrm{RO}_{2} \mathrm{H}$ (this reaction regenerates the chain carrier $R^{\circ}$ and, under certain conditions, can be viewed as being reversible [6]) or the alcohol $\mathrm{ROH}$ (this is followed by the regeneration of $R^{\cdot}$ via reaction $3 b$ ). The latter (alternative) pathway of reaction 3 consists of four steps, namely, the breaking of old bonds and the formation of two new bonds in the reacting structures. In reaction $3 \mathrm{a}$, the isomerization and decomposition of the alkylperoxyl radical adduct $\mathrm{RO}_{2}^{*}$ with $\mathrm{O}-\mathrm{O}$ and $\mathrm{C}-\mathrm{O}$ or $\mathrm{C}-\mathrm{H}$ bond breaking take place $[5,9]$, yielding the carbonyl compound $\mathrm{R}_{(-\mathrm{H})} \mathrm{HO}$ or $\mathrm{R}_{(-2 \mathrm{H})} \mathrm{HO}$. Reaction $3 \mathrm{~b}$ produces the alcohol $\mathrm{R}^{\prime \prime} \mathrm{OH}$ or water and regenerates the free radical $R^{\circ}$ (here, $R^{\prime}$ and $R^{\prime \prime}$ are radicals having a smaller number of carbon atoms than $R$ ). As follows from the above scheme of the process, consecutive reactions $3 a$ and $3 b$ (whose rates are equal within the quasi-steady-state treatment), in which the highly reactive fragment, oxyl radical $\mathrm{R}^{\prime \prime} \mathrm{O}^{\circ}$ (or ${ }^{\circ} \mathrm{OH}$ ) forms and then disappears, respectively, can be represented as a single, combined bimolecular reaction $3 a, b$ occurring in a "cage" of solvent molecules. Likewise, the alternative (parenthesized) pathways of reactions 3 and $3 \mathrm{~b}$, which involve the alkoxyl radical $\mathrm{RO}^{\circ}$, can formally be treated as having equal rates. For simple alkyl $\mathrm{C}_{1}-\mathrm{C}_{4}$ radicals $R$, the pathway of reaction 3 leading to the alkyl hydroperoxide $\mathrm{RO}_{2} \mathrm{H}$ is endothermic $\left(\Delta H_{298}^{\circ}=30-80\right.$ $\mathrm{kJ} \mathrm{mol}^{-1}$ ) and the alternative pathway yielding the alcohol $\mathrm{ROH}$ is exothermic $\left(\Delta H_{298}^{\circ}=-120\right.$ to $-190 \mathrm{~kJ}$ $\mathrm{mol}^{-1}$ ), while the parallel reaction $3 \mathrm{a}$, which yields a carbonyl compound and the alkoxyl radical $\mathrm{R}^{\prime \prime} \mathrm{O}^{\circ}$ or the hydroxyl radical ${ }^{\circ} \mathrm{OH}$, is exothermic in both cases $\left(\Delta H_{298}^{\circ}=-80\right.$ to $-130 \mathrm{~kJ} \mathrm{~mol}^{-1}$ ), as also is reaction $3 \mathrm{~b}$ $\left(\Delta H_{298}^{\circ}=-10\right.$ to $\left.-120 \mathrm{~kJ} \mathrm{~mol}^{-1}\right)$, consecutive to reaction $3 \mathrm{a}$, according to thermochemical data for the 
gas phase $[6,17,18]$. In reaction 4 , which is competing with (parallel to) reactions 3 and $3 a$ (chain propagation through the reactive radical $R^{*}$ ), the resulting lowreactive radical that does not participate in further chain propagation and inhibits the chain process is supposed to be the alkyltetraoxyl 1:2 radical adduct ${ }^{2,3} \mathrm{RO}_{4}^{-}$, which has the largest weight and size. This radical is possibly stabilized by a weak intramolecular $\mathrm{H} \cdots \mathrm{O}$ hydrogen bond [25] shaping it into a six-membered cyclic structure $^{4}$ (seven-membered cyclic structure in the case of aromatic and certain branched acyclic hydrocarbons) [27, 28]:

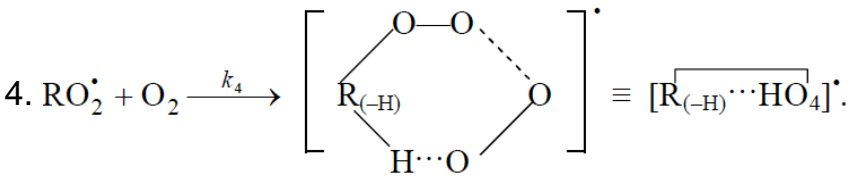

Reaction 4 in the case of the methylperoxyl radical $\mathrm{CH}_{3} \mathrm{O}_{2}^{*}$ adding to the oxygen molecule to yield the methyltetraoxyl radical $\mathrm{CH}_{3} \mathrm{O}_{4}^{\circ}$ takes place in the gas phase, with heat absorption equal to $110.0 \pm 18.6 \mathrm{~kJ}$ $\mathrm{mol}^{-1}$ [20] (without the energy of the possible formation of a hydrogen bond taken into account). The exothermic reactions 6 and 7 , in which the radical $R^{\circ}$ or $\mathrm{RO}_{4}^{\bullet}$ undergoes disproportionation, include the isomerization and decomposition of the $\mathrm{RO}_{4}^{\circ}$ radical. The latter process is likely accompanied by chemiluminescence typical of hydrocarbon oxidation [23]. These reactions regenerate oxygen as $\mathrm{O}_{2}$ molecules (including singlet oxygen ${ }^{5}[23,30]$ ) and, partially, as $\mathrm{O}_{3}$ molecules and yield the carbonyl compound $\mathrm{R}_{(-2 \mathrm{H})} \mathrm{HO}$ (possibly in the triplet excited state [23]). Depending on the decomposition pathway, the other possible products are the alcohol $\mathrm{ROH}$, the olefin

\footnotetext{
${ }^{2}$ It is hypothesized that raising the oxygen concentration in the o-xyleneoxygen system can lead to the formation of an $\left[\mathrm{ROO}^{\circ} \mathrm{NO}_{2}\right]$ intermediate complex [11] similar to the $\left[\mathrm{ROO}^{\circ} \cdots(\pi\right.$-bond) $\mathrm{RH}]$ complex between the alkylperoxyl 1:1 adduct radical and an unsaturated hydrocarbon suggested in this work. The electronic structure of the $\pi$-complexes is considered elsewhere [19].

${ }^{3}$ Thermochemical data are available for some polyoxyl free radicals (the enthalpy of formation of the methyltetraoxyl radical without the energy of the possible intramolecular hydrogen bond $\mathrm{H} \cdots \mathrm{O}$ taken into account is $\left.\Delta H_{f 298}^{\circ}\left(\mathrm{CH}_{3} \mathrm{O}_{4}^{\circ}\right)=121.3 \pm 15.3 \mathrm{~kJ} \mathrm{~mol}^{-1}\right)$ and polyoxides $\left(\Delta H_{f}^{\circ}{ }_{298}\left(\mathrm{CH}_{3} \mathrm{O}_{4} \mathrm{H}\right)=-\right.$ $21.0 \pm 9 \mathrm{~kJ} \mathrm{~mol}^{-1}$ ) [20]. These data were obtained using the group contribution approach. Some physicochemical and geometric parameters were calculated for the methyl hydrotetraoxide molecule as a model compound [21-23]. The IR spectra of dimethyl tetraoxide with isotopically labeled groups in $\mathrm{Ar}-\mathrm{O}_{2}$ matrices were also reported [24]. For reliable determination of the number of oxygen atoms in an oxygen-containing species, it is necessary to use IR and EPR spectroscopy in combination with the isotope tracer method [24].

${ }^{4} \mathrm{An} \mathrm{R}_{(-\mathrm{H})} \mathrm{H} \cdots \mathrm{O}(\mathrm{R}) \mathrm{O}_{3}$ ring consisting of the same six atoms $(\mathrm{C}, \mathrm{H}$, and $4 \mathrm{O})$, presumably with a hydrogen bond [5], also forms in the transition state of the dimerization of alkylperoxyl radicals $\mathrm{RO}_{2}^{*}$ via the Russell mechanism $[7,26]$.

${ }^{5}$ Note that the alkylperoxyl radicals $\mathrm{RO}_{2}^{*}$ are effective quenchers of singlet oxygen $\mathrm{O}_{2}\left(a_{1} \Delta_{g}\right)$ [29]
}

$\mathrm{R}_{(-2 \mathrm{H})} \mathrm{H}$ (in the case of the oxidation of a saturated hydrocarbon), the ether ROR, the alkyl peroxide $\mathrm{RO}_{2} \mathrm{R}$, hydrogen peroxide, and water. It is likely that the isomerization and decomposition of the $\mathrm{RO}_{4}^{\circ}$ radical via reactions 6 and 7 can take place through the breaking of a $\mathrm{C}-\mathrm{C}$ bond to yield carbonyl compounds, alcohols, ethers, and organic peroxides containing fewer carbon atoms than the initial hydrocarbon, as in the case of the alkylperoxyl radical $\mathrm{RO}_{2}^{*}$ in reaction $3 \mathrm{a}$. At later stages of oxidation and at sufficiently high temperatures, the resulting aldehydes can be further oxidized into respective carboxylic acids. They can also react with molecular oxygen so that a $\mathrm{C}-\mathrm{H}$ bond in the aldehyde molecule breaks to yield two free radicals $\left(\mathrm{HO}_{2}^{*}\right.$ and ${ }^{\circ} \mathrm{R}_{(-\mathrm{H})} \mathrm{O}$ or $\left.{ }^{\cdot} \mathrm{R}_{(-2 \mathrm{H})} \mathrm{O}\right)$. This process, like possible ozone decomposition yielding an ${ }^{\circ} \mathrm{O}^{\circ}$ atom or peroxide decomposition with $\mathrm{O}-\mathrm{O}$ bond breaking, leads to degenerate chain branching [5].

The equations describing the formation rates of molecular products at the chain propagation and termination stages of the above reaction Scheme 1, set up using the quasi-steady-state treatment ${ }^{6}$, appear as follows:

$$
\begin{gathered}
V_{3}\left(\mathrm{RO}_{2} \mathrm{H} ; \mathrm{ROH}\right)=V_{1} \alpha l k_{2} x / f= \\
=V_{1} \alpha l x / f_{m}, \\
V_{3 \mathrm{a}}\left(\mathrm{R}_{(-\mathrm{H})} \mathrm{HO} ; \mathrm{R}_{(-2 \mathrm{H})} \mathrm{HO}\right)=V_{3 \mathrm{~b}}\left(\mathrm{R}^{\prime \prime} \mathrm{OH} ; \mathrm{H}_{2} \mathrm{O}\right)= \\
=V_{1} \beta k_{2} x / f= \\
=V_{1} \beta x / f_{m}, \\
2 V_{6}=2 V_{1} \sqrt{2 k_{5} V_{1}}(\alpha l+\beta+x) k_{2} x^{2} / f^{2}, \\
V_{7}=V_{1}\left(k_{2} x^{2}\right)^{2} / f^{2},
\end{gathered}
$$

where $V_{1}$ is the initiation rate, $I=[\mathrm{RH}]$ and $x=\left[\mathrm{O}_{2}\right]$ are the initial molar concentrations of the starting components $(I>>x), \alpha=k_{3} / k_{4}$ and $\beta=k_{3 a} / k_{4}\left(\mathrm{~mol} \mathrm{dm}^{-3}\right)$ are the ratios of the rate constants of the competing (parallel) reactions, $k_{2}=\left(\alpha l_{m}+\beta\right) \sqrt{2 k_{5} V_{1}} / x_{m}^{2}$ is the rate constant of the addition of the alkyl radical $\mathrm{R}^{\circ}$ to the oxygen molecule (reaction 2) as determined by solving

\footnotetext{
${ }^{6}$ In order to reduce the exponent of the $2 k_{5}\left[R^{*}\right]^{2}$ term in the $d\left[R^{\circ}\right] / d t=0$ equation to unity [1], we used the following condition for the early stages of the process: $k_{6}=\sqrt{2 k_{5} 2 k_{7}}$ [8] and, hence, $V_{1}=V_{5}+2 V_{6}+V_{7}=\left(\left[\mathrm{R}^{*}\right]+\left[\mathrm{RO}_{4}^{*}\right]\right)^{2}$.
} 
the quadratic equation following from the rate function extremum condition $\partial V_{3,3 a} / \partial x=0, I_{m}$ and $x_{m}$ are the values of $I$ and $x$ at the maximum point of the function, $f=k_{2} x^{2}+(\alpha l+\beta+x) \sqrt{2 k_{5} V_{1}}$, and $f_{m}=x^{2}+(\alpha l+\beta+x) x_{m}^{2} /\left(\alpha l_{m}+\beta\right)$.

The ratios of the rates of the competing reactions are $V_{3} / V_{4}=\alpha l / x$ and $V_{3 a} / V_{4}=\beta / x$, and the chain length is $v=\left(V_{3}+V_{3 \mathrm{a}}\right) / V_{1}$. The overall rate of the process is a complicated function of the formation and disappearance rates of the free radicals $\mathrm{R}^{\circ}$ and $\mathrm{RO}_{4}^{\circ}$ : $V\left(\mathrm{RO}_{2} \mathrm{H}, \mathrm{R}_{(-\mathrm{H})} \mathrm{HO}, \mathrm{R} " \mathrm{OH} ; \mathrm{ROH} ; \mathrm{R}_{(-2 \mathrm{H})} \mathrm{HO}, \mathrm{H}_{2} \mathrm{O}\right)=V_{1 \mathrm{a}}+$ $V_{3}+V_{3 b}-V_{4}-V_{5}-V_{7}$. As distinct from the rates $V_{4}\left(V_{4}\right.$ $\left.\leq V_{1}\right), V_{5}$, and $V_{7}$, the rates $V_{2}, V_{3}, V_{3 a}$, 3b and $2 V_{6}$ as a function of the concentration $x$ have a maximum.

Eqs (1a) and (2a) were obtained by replacing the rate constant $k_{2}$ in Eqs. (1) and (2) with its analytical expression (for reducing the number of unknown parameters to be determined directly).

For $\alpha l>>\beta\left(V_{3}>>V_{3 a}\right)$, when the total yield of alkyl hydroperoxides and alcohols having the same number of carbon atoms as the initial compound far exceeds the yield of carbonyl compounds, as in the case of the oxidation of some hydrocarbons, the parameter $\beta$ in Eqs. (1) and (1a) can be neglected $(\beta=0): f=k_{2} X^{2}+$ $(\alpha l+x) \sqrt{2 k_{5} V_{1}}, \quad f_{m}=x^{2}+(\alpha l+x) x_{m}^{2} / \alpha l_{m}, \quad$ and $k_{2}=\alpha l_{m} \sqrt{2 k_{5} V_{1}} / x_{m}^{2}$.

Equations (1) and (2) subject to the constraint $k_{2} x^{2}$ $>(\alpha I+\beta+x) \sqrt{2 k_{5} V_{1}}$ (the descending branch of the peaking curve) can be transformed into Eqs. (6) and (7), respectively, which express simple inverse proportionalities with respect to the initial oxygen concentration $x$ and allow the parameters $\alpha$ and $\beta$ to be tentatively estimated from the experimental product formation rate $V$ provided that $V_{1}$ is known:

$$
\begin{aligned}
& V_{3}=V_{1} \alpha l / \varphi x, \\
& V_{3 a}=V_{1} \beta / \varphi x,
\end{aligned}
$$

where $\varphi=2$ at the point of maximum (where $k_{2} x^{2} \cong(\alpha)$ $+\beta+x) \sqrt{2 k_{5} V_{1}}$ ) and $\varphi=1$ for the descending branch of the curve.

In the alternative kinetic model of oxidation, whose chain termination stage involves, in place of $R^{\cdot}$ (Scheme 1), $\mathrm{RO}_{2}^{*}$ radicals reacting with one another and with $\mathrm{RO}_{4}^{\cdot}$ radicals, the dependences of the chain formation rates of the products on the oxygen concentration $x$ derived by the same method have no maximum: $\quad V_{3}=V_{1} k_{3} l /\left(k_{4} x+\sqrt{\left.2 k_{5_{1}} V_{1}\right)} \quad\right.$ and $V_{3 \mathrm{a}}=V_{1} k_{3 \mathrm{a}} /\left(k_{4} x+\sqrt{2 k_{5} V_{1}}\right)$. In the kinetic model of oxidation that does not include the competing reaction $4\left(k_{4}=0\right)$ and involves the radicals $\mathrm{R}^{\circ}$ and $\mathrm{RO}_{2}^{\cdot}$ (the latter instead of $\mathrm{RO}_{4}^{\cdot}$ in Scheme 1) in reactions 5-7, the reaction rate functions $V_{3}$ and $V_{3 a}$ obtained in the same way are fractional rational functions in the form of $a_{0} x /\left(b_{0} x+c_{0}\right)$, where $a_{0}, b_{0}$, and $c_{0}$ are coefficients having no extremum. For a similar kinetic model in which reactions $3 a, b$ and 4 appearing in the above scheme are missing $\left(k_{3 a}=k_{4}=0\right)$, Walling [7], using the quasi-steady-state treatment in the long kinetic chain approximation, when it can be assumed that $V_{2}=$ $V_{3}$, without using the substitution $k_{6}=\sqrt{2 k_{5} 2 k_{7}}[5,7,8]$ (as distinct from this work), found that $V_{2}=V_{3}$ is an irrational function of $x: a_{1} x / \sqrt{b_{1} x^{2}+c_{1} x+d_{1}}$ where $a_{1}$, $b_{1}, c_{1}$, and $d_{1}$ are coefficients. Again, this function has no maximum with respect to the concentration of any of the two components.

Thus, of the three kinetic models of oxidation mathematically analyzed above, which involve the radicals $\mathrm{R}^{\cdot}$ and $\mathrm{RO}_{2}^{*}$ in three types of quadratic-law chain termination reactions (reactions 5-7) and are variants of the conventional model [5-10], the last two lead to an oxidation rate versus oxygen concentration curve that emanates from the origin of coordinates, is convex upward, and has an asymptote parallel to the abscissa axis. Such monotonic dependences are observed when the oxygen solubility in the liquid is limited under given experimental conditions and the oxygen concentration attained ${ }^{7}$ is $\left[\mathrm{O}_{2}\right]_{\text {top }} \leq x_{\mathrm{m}}$.

Unlike the conventional model, the above kinetic model of free-radical nonbranched-chain oxidation, which includes the pairs of competing reactions 3-4 and 3a-4 (Scheme 1), allows us to describe the nonmonotonic (peaking) dependence of the oxidation rate on the oxygen concentration (Figure 1). In this oxidation model, as the oxygen concentration in the binary system is increased, oxygen begins to act as an oxidation autoinhibitor or an antioxidant via the further oxidation of the alkylperoxyl 1:1 adduct radical $\mathrm{RO}_{2}^{*}$ into the low-reactive $1: 2$ adduct radical $\mathrm{RO}_{4}^{\circ}$ (reactions 4 and 6 lead to inefficient consumption of the free radicals $\mathrm{RO}_{2}^{*}$ and $\mathrm{R}^{*}$ and cause shortening of the

\footnotetext{
${ }^{7}$ The oxygen concentration attained in the liquid may be below the thermodynamically equilibrium oxygen concentration because of diffusion limitations hampering the establishment of the gas-liquid saturated solution equilibrium under given experimental conditions (for example, when the gas is bubbled through the liquid) or because the Henry law is violated for the given gas-liquid system under real conditions.
} 
kinetic chains). The optimum oxygen concentration $x_{m}$, at which the oxidation rate is the highest, can be calculated using kinetic equations (1a) and (2a) or the corresponding analytical expression for $k_{2}$. In the familiar monograph Chain Reactions by Semenov [31], it is noted that raising the oxygen concentration when it is already sufficient usually slows down the oxidation process by shortening the chains. The existence of the upper (second) ignition limit in oxidation is due to chain termination in the bulk through triple collisions between an active species of the chain reaction and two oxygen molecules (at sufficiently high oxygen partial pressures). In the gas phase at atmospheric pressure, the number of triple collisions is roughly estimated to be $10^{3}$ times smaller than the number of binary collisions (and the probability of a reaction taking place depends on the specificity of the action of the third particle).

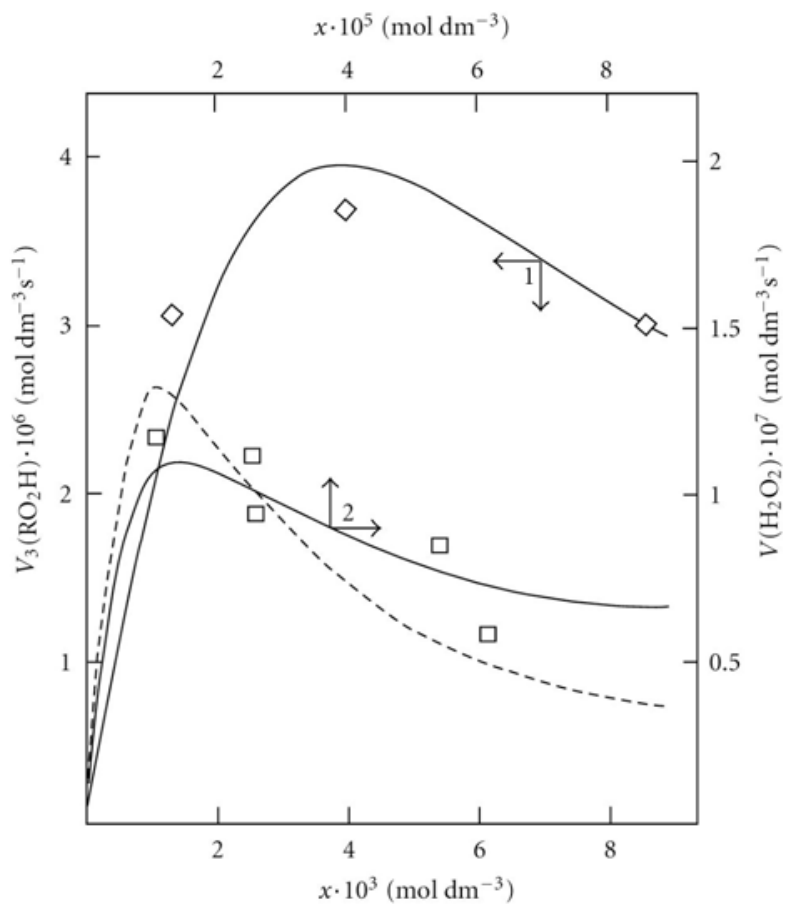

Figure 1: $(1, \diamond)$ Reconstruction of the functional dependence of the 2-methylbenzyl hydroperoxide formation rate $V_{3}\left(\mathrm{RO}_{2} \mathrm{H}\right)$ on the initial dissolved oxygen concentration $x$ from empirical data (points) using Eq. (1a) with $\beta=0$ (model optimization with respect to the parameter $\alpha$ ) for the o-xylene-oxygen system at $373 \mathrm{~K}$ [11] (standard deviation of $S_{Y}=5.37 \times 10^{-7}$ ). $(2, \square)$ Reconstruction of the functional dependence of the total hydrogen peroxide formation rate $V_{3,7}\left(\mathrm{H}_{2} \mathrm{O}_{2}\right)$ on the initial dissolved oxygen concentration $x$ from empirical data (symbols) using Eqs. (1a) and (5a) with $\beta=0$ (model optimization with respect to the parameter $\alpha$ ) for the $\mathrm{Y}^{-}$ radiolysis of water saturated with hydrogen and containing different amounts of oxygen at $296 \mathrm{~K}[34]\left(S_{Y}=1.13 \times 10^{-8}\right)$. The dashed curve described $V_{3}\left(\mathrm{RO}_{2} \mathrm{H}\right)$ as a function of the initial oxygen concentration $x$ based on Eq. (1a) with $\beta=0$ (model optimization with respect to $\alpha$ ) and the experimental data of curve $2\left(S_{Y}=1.73 \times 10^{-8}\right)$.
Curve 1 in Figure 1 illustrates the fit between Eq. (1a) at $\alpha l>>\beta$ and experimental data for the radiationinduced oxidation of $o$-xylene in the liquid phase at 373 $\mathrm{K}$ in the case of 2-methylbenzyl hydroperoxide forming much more rapidly than o-tolualdehyde $\left(V_{3}>>V_{3 a}\right.$ and $\alpha l>>\beta$, i.e., the parameter $\beta$ can be neglected) [11]. The oxygen concentration limit in $o$-xylene is reached at an oxygen concentration of $\left[\mathrm{O}_{2}\right]_{\text {top }}>x_{m}$, which corresponds to the third experimental point [11]. The oxygen concentration was calculated from the oxygen solubility in liquid xylene at $373 \mathrm{~K}$ [32]. The following quantities were used in this mathematical description: ${ }^{60} \mathrm{Co} \gamma$-radiation dose rate of $P=2.18 \mathrm{~Gy} \mathrm{~s}^{-1}$ and total initiation yield of $\mathrm{G}\left(0-\mathrm{CH}_{3} \mathrm{C}_{6} \mathrm{H}_{4} \dot{\mathrm{C}} \mathrm{H}_{2}\right)=2.6$ particles per $100 \mathrm{eV}$ of the energy absorbed by the solution [11]; $V_{1}$ $=4.73 \times 10^{-7} \mathrm{~mol} \mathrm{dm}^{-3} \mathrm{~s}^{-1}$, and $2 k_{5}=1.15 \times 10^{10} \mathrm{dm}^{3}$ $\mathrm{mol}^{-1} \mathrm{~s}^{-1}$. The resulting value of the parameter $\alpha$ is $(9.0$ $\pm 1.8) \times 10^{-3}$; hence, $k_{2}=(3.2 \pm 0.8) \times 10^{5} \mathrm{dm}^{3} \mathrm{~mol}^{-1}$ $\mathrm{s}^{-1}$. From data presented in [33], was estimated that $k_{4}$ $=k_{3} / \alpha=(5.2 \pm 1.2) \times 10^{2} \mathrm{dm}^{3} \mathrm{~mol}^{-1} \mathrm{~s}^{-1}$.

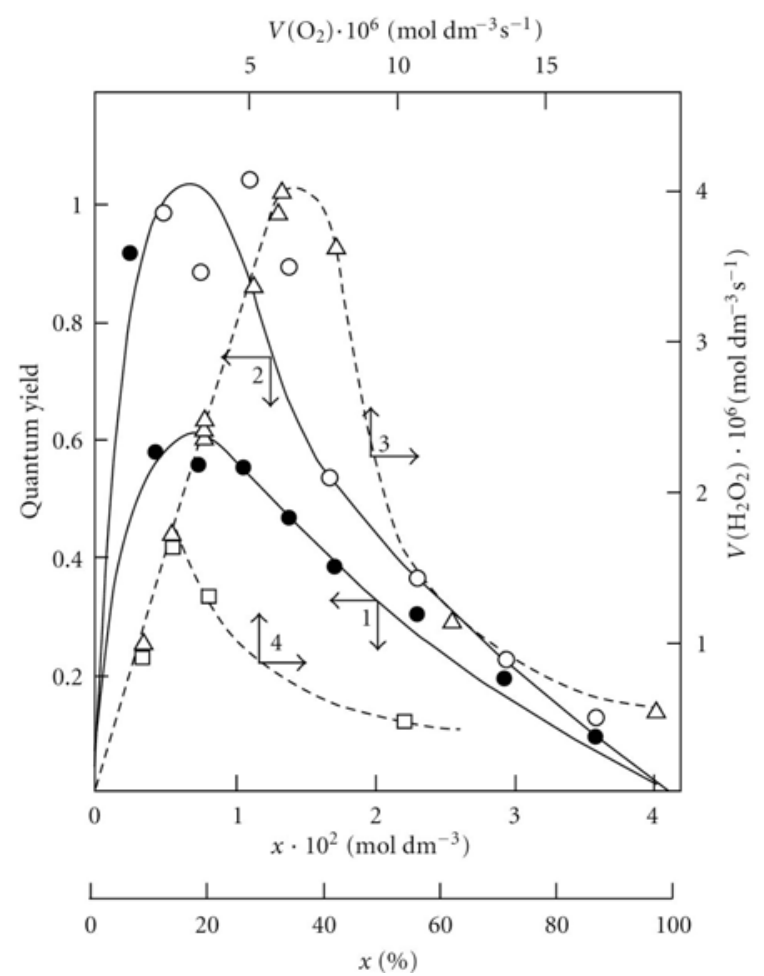

Figure 2: $(1,2)$ Quantum yields of $(1, \bullet)$ hydrogen peroxide and $(2, \circ)$ water resulting from the photochemical oxidation of hydrogen in the hydrogen-oxygen system as a function of the initial oxygen concentration $x_{5}$ (light wavelength of 171.9 $172.5 \mathrm{~nm}$, total pressure of $10^{5} \mathrm{~Pa}$, room temperature [35]). $(3,4)$ Hydrogen peroxide formation rate $V\left(\mathrm{H}_{2} \mathrm{O}_{2}\right)$ (dashed curves) as a function of the rate $V\left(\mathrm{H}_{2} \mathrm{O}_{2}\right)$ at which molecular oxygen is passed through a gas-discharge tube filled with (3, $\triangle)$ atomic and $(4, \square)$ molecular hydrogen. Atomic hydrogen was obtained from molecular hydrogen in the gas-discharge tube before the measurements (total pressure of 25-77 Pa, temperature of $77 \mathrm{~K}$ [12]). The symbols represent experimental data. 


\section{ADDITION OF THE HYDROGEN ATOM}

A number of experimental findings concerning the autoinhibiting effect of an increasing oxygen concentration at modest temperatures on hydrogen oxidation both in the gas phase [12, 35, 36] (Figure 2) and in the liquid phase [34] (Figure 1, curve 2), considered in our earlier works [13, 27, 28, 37], can also be explained in terms of the competition kinetics of free radical addition [14, 38].

The hydroperoxyl free radical $\mathrm{HO}_{2}^{*}$ [46-50] resulting from reaction 2 possesses an increased energy due to

Chain initiation

1. $\mathrm{H}_{2} \stackrel{h v, \gamma}{\longrightarrow} 2 \mathrm{H}^{*}$,

$$
\Delta H_{298}^{\circ}=436.0 \pm 0.0 .
$$

Chain propagation

$$
2 . \mathrm{H}^{\cdot}+\mathrm{O}_{2} \stackrel{k_{2}}{\longrightarrow} \mathrm{HO}_{2}^{\cdot} \text {, }
$$$$
\Delta H_{298}^{\circ}=-205.4 \pm 1.7 \text {; }
$$$$
\text { 3. } \mathrm{HO}_{2}^{*}+\mathrm{H}_{2} \stackrel{k_{3}}{\longrightarrow} \mathrm{H}_{2} \mathrm{O}+\mathrm{HO}^{*} \text {, }
$$$$
\Delta H_{298}^{\circ}=-215.4 \pm 2.9
$$$$
\text { (or } \mathrm{H}_{2} \mathrm{O}_{2}+\mathrm{H}^{\cdot} \text {, }
$$

$$
\Delta H_{298}^{\circ}=69.4 \pm 1.7
$$

$3^{\prime} . \mathrm{HO}^{*}+\mathrm{H}_{2} \stackrel{k_{3}^{\prime}}{\longrightarrow} \mathrm{H}_{2} \mathrm{O}+\mathrm{H}^{*}$,

$$
\Delta H_{298}^{\circ}=62.8 \pm 1.2 \text {. }
$$

Inhibition

$$
\text { 4. } \mathrm{HO}_{2}^{-}+\mathrm{O}_{2} \stackrel{k_{4}}{\longrightarrow} \mathrm{HO}_{4}^{\cdot}
$$

$$
\Delta H_{298}^{\circ}=110.0 \pm 15.4
$$

Chain termination

$$
\begin{array}{rrr}
5.2 \mathrm{H}^{\circ}(+\mathrm{M}) \stackrel{2 k_{5}}{\longrightarrow} \mathrm{H}_{2}(+\mathrm{M}) & \Delta H_{298}^{\circ}=-436.0 \pm 0.0 ; \\
6 . \mathrm{H}^{\circ}+\mathrm{HO}_{4}^{\circ} \stackrel{k_{6}}{\longrightarrow} \mathrm{H}_{2} \mathrm{O}_{2}+\mathrm{O}_{2}, & \Delta H_{298}^{\circ}=-476.6 \pm 13.7 \\
\left(\text { or }: \mathrm{H}_{2} \mathrm{O}+\mathrm{O}_{3},\right. & \Delta H_{298}^{\circ}=-439.3 \pm 15.4, \\
\left.\mathrm{H}_{2}+2 \mathrm{O}_{2}\right), & \Delta H_{298}^{\circ}=-340.6 \pm 13.7 ; \\
7.2 \mathrm{HO}_{4}^{\circ} \stackrel{2 k_{7} \longrightarrow}{\longrightarrow} \mathrm{H}_{2} \mathrm{O}_{2}+3 \mathrm{O}_{2}, & \Delta H_{298}^{\circ}=-381.2 \pm 27.4 \\
\left(\text { or }: \mathrm{H}_{2} \mathrm{O}+\mathrm{O}_{3}+2 \mathrm{O}_{2},\right. & \Delta H_{298}^{\circ}=-343.9 \pm 29.1, \\
\mathrm{H}_{2} \mathrm{O}_{2}+2 \mathrm{O}_{3}, & \Delta H_{298}^{\circ}=-95.0 \pm 30.8, \\
\left.\mathrm{H}_{2}+4 \mathrm{O}_{2}\right), & \Delta H_{298}^{\circ}=-245.2 \pm 27.4 .
\end{array}
$$

Scheme 2: Nonbranched-chain oxidation of hydrogen and changes in enthalpy $\left(\Delta H_{298}^{\circ}, \mathrm{kJ} \mathrm{mol}^{-1}\right)$ for elementary reactions ${ }^{8}$.

\footnotetext{
${ }^{8}$ According to Francisco and Williams [20], the enthalpy of formation $\left(\Delta H_{f}{ }^{\circ 298}\right)$ in the gas phase of $\mathrm{H}^{\circ}, \mathrm{HO}^{\circ}, \mathrm{HO}_{2}^{*}, \mathrm{HO}_{4}^{*}$ (the latter without the possible intramolecular hydrogen bond taken into account), $\mathrm{O}_{3}, \mathrm{H}_{2} \mathrm{O}$ [6], $\mathrm{H}_{2} \mathrm{O}_{2}$, and $\mathrm{H}_{2} \mathrm{O}_{4}$ is $218.0 \pm 0.0,39.0 \pm 1.2,12.6 \pm 1.7,122.6 \pm 13.7,143.1 \pm 1.7,-241.8 \pm 0.0,-$ $136.0 \pm 0$, and $-26.0 \pm 9 \mathrm{~kJ} \mathrm{~mol}^{-1}$, respectively. Calculations for the $\mathrm{HO}_{4}^{-}$ radical with a helical structure were carried out using the G2(MP2) method [39]. The stabilization energies of $\mathrm{HO}_{2}^{+}, \mathrm{HO}_{4}^{-}$, and $\mathrm{HO}_{3}^{*}$ were calculated in the same work to be $64.5 \pm 0.1,69.5 \pm 0.8$, and $88.5 \pm 0.8 \mathrm{~kJ} \mathrm{~mol}^{-1}$, respectively. The types of the $\mathrm{O}_{4}$ molecular dimers, their IR spectra, and higher oxygen oligomers were reported [40, 41]. The structure and IR spectrum of the hypothetical cyclotetraoxygen molecule $\mathrm{O}_{4}$, a species with a high energy density, were calculated by the CCSD method, and its enthalpy of formation was estimated [42]. The photochemical properties of $\mathrm{O}_{4}$ and the van der Waals nature of the $\mathrm{O}_{2}-\mathrm{O}_{2}$ bond were investigated $[43,44]$. The most stable geometry of the dimer is two $\mathrm{O}_{2}$ molecules parallel to one another. The $\mathrm{O}_{4}$ molecule was identified by NR mass spectrometry [45].
}

the energy released the conversion of the $\mathrm{O}=\mathrm{O}$ double bond into an $\mathrm{HO}-\mathrm{O}^{\circ}$ ordinary bond. Therefore, before its possible decomposition, it can interact with a hydrogen or oxygen molecule as the third body via parallel (competing) reactions 3 and 4 , respectively. The hydroxyl radical $\mathrm{HO}^{\circ}$ that appears and disappears in consecutive parallel reactions 3 (first variant) and $3^{\prime}$ possesses additional energy owing to the exothermicity of the first variant of reaction 3 , whose heat is distributed between the two products. As a consequence, this radical has a sufficiently high reactivity not to accumulate in the system during these reactions, whose rates are equal $\left(V_{3}=V_{3}\right)$ under quasisteady-state conditions, according to the above scheme. Parallel reactions 3 (second, parenthesized variant) and $3^{\prime}$ regenerate hydrogen atoms. It is assumed $[27,28]$ that the hydrotetraoxyl radical $\mathrm{HO}_{4}^{\circ}$ (first reported in [51-53]) resulting from endothermic reaction 4, which is responsible for the peak in the experimental rate curve (Figure 2, curve 3), is closed into a five-membered [OO- $\left.\mathrm{H}^{\cdots} \mathrm{OO}\right]^{\bullet}$ cycle due to weak intramolecular hydrogen bonding [25, 54]. This structure imparts additional stability to this radical and makes it least reactive.

The $\mathrm{HO}_{4}^{-}$radical was discovered by Staehelin et al. [55] in a pulsed radiolysis study of ozone degradation in water; its UV spectrum with an absorption maximum at $260 \mathrm{~nm}\left(\varepsilon\left(\mathrm{HO}_{4}^{\circ}\right)_{280 \mathrm{~mm}}=320 \pm 15 \mathrm{~m}^{2} \mathrm{~mol}^{-1}\right)$ was reported. The spectrum of the $\mathrm{HO}_{4}^{-}$radical is similar to that of ozone, but the molar absorption coefficient $\varepsilon\left(\mathrm{HO}_{4}^{*}\right)_{\lambda \max }$ of the former is almost two times larger [55]. The assumption about the cyclic structure of the $\mathrm{HO}_{4}^{-}$radical can stem from the fact that its mean lifetime in water at $294 \mathrm{~K}$, which is $(3.6 \pm 0.4) \times 10^{-5} \mathrm{~s}$ (as estimated [37] from the value of $1 / k$ for the monomolecular decay reaction $\mathrm{HO}_{4}^{-} \stackrel{k}{\longrightarrow} \mathrm{HO}_{2}^{*}+\mathrm{O}_{2}$ [55]), is 3.9 times longer than that of the linear $\mathrm{HO}_{3}^{*}$ radical $[39,56]$ estimated in the same way [37] for the same conditions [57], $(9.1 \pm 0.9) \times 10^{-6} \mathrm{~s}$.

MP2/6-311++ $\mathrm{G}^{* *}$ calculations using the Gaussian98 program confirmed that the cyclic structure of $\mathrm{HO}_{4}^{*}$ [58] is energetically more favorable than the helical structure [39] (the difference in energy is $4.8-7.3 \mathrm{~kJ}$ $\mathrm{mol}^{-1}$, depending on the computational method and the basis set) $)^{9}$. For example, with the MP2(full)/6-31G(d)

\footnotetext{
${ }^{9}$ There were calculations for the two conformers (cis and trans) of the $\mathrm{HO}_{4}^{*}$ radical [59] using large scale ab initio methods and density functional techniques with extended basis sets. Both conformers have a nearly planar geometry with respect to the four oxygen atoms and present an unusually long central O-O bond. The most stable conformer of $\mathrm{HO}_{4}^{-}$radical is the cis one, which is computed to be endothermic with respect to $\mathrm{HO}_{2}^{-}\left(X^{2} A^{\prime \prime}\right)+\mathrm{O}_{2}\left(X^{3} \Sigma_{\mathrm{g}}^{-}\right)$at $0 \mathrm{~K}$
} 
method, the difference between the full energies of the cyclic and acyclic $\mathrm{HO}_{4}^{-}$conformers with their zero-point energies (ZPE) values taken into account (which reduces the energy difference by $1.1 \mathrm{~kJ} \mathrm{~mol}^{-1}$ ) is -5.1 $\mathrm{kJ} \mathrm{mol}^{-1}$ and the entropy of the acyclic-to-cyclic $\mathrm{HO}_{4}^{\circ}$ transition is $\Delta \mathrm{S}_{298}^{\circ}=-1.6 \mathrm{~kJ} \mathrm{~mol}^{-1} \mathrm{~K}^{-1}$. Therefore, under standard conditions, $\mathrm{HO}_{4}^{-}$can exist in both forms, but the cyclic structure is obviously dominant $\left(87 \%, K_{e q}=\right.$ 6.5) [58].

Reaction 4 and, to a much lesser degree, reaction 6 inhibit the chain process, because they lead to inefficient consumption of its main participants $-\mathrm{HO}_{2}^{\circ}$ and $\mathrm{H}^{\circ}$.

The hydrogen molecule that results from reaction 5 in the gas bulk possesses an excess energy, and, to acquire stability within the approximation used in this work, it should have time for deactivation via collision with a particle $M$ capable of accepting the excess energy [60]. To simplify the form of the kinetic equations, it was assumed that the rate of the bimolecular deactivation of the molecule substantially exceeds the rate of its monomolecular decomposition, which is the reverse of reaction 5 [6].

Reactions 6 and 7 regenerate hydrogen and oxygen (in the form of $\mathrm{O}_{2}\left(\mathrm{X}^{3} \Sigma_{\mathrm{g}}^{-}\right)$molecules, including the singlet states with $\Delta H_{\mathrm{f} 298}^{\circ}\left(\mathrm{O}_{2}, a^{1} \Delta_{\mathrm{g}}\right)=94.3 \mathrm{~kJ} \mathrm{~mol}^{-1}$ $[20,41]$ and $\Delta H_{\mathrm{f} 298}^{\circ}\left(\mathrm{O}_{2}, b^{1} \Sigma_{\mathrm{g}}^{+}\right)=161.4 \mathrm{~kJ} \mathrm{~mol}^{-1}[41]$, which are deactivated by collisions, and in the form of $\mathrm{O}_{3}$ ) and yield hydrogen peroxide or water via a nonchain mechanism, presumably through the intermediate formation of the unstable hydrogen tetraoxide molecule $\mathrm{H}_{2} \mathrm{O}_{4}[61,62]^{10}$. Ozone does not interact with molecular hydrogen. At moderate temperatures, it decomposes fairly slowly, particularly in the presence of $\mathrm{O}_{2}\left(\mathrm{X}^{3} \Sigma_{\mathrm{g}}^{-}\right)$[41]. The reaction of ozone with $\mathrm{H}^{\circ}$ atoms, which is not impossible, results in their replacement with $\mathrm{HO}^{\circ}$ radicals. The relative contributions from reactions 6 and 7 to the process kinetics can be roughly estimated from the corresponding enthalpy increments (Scheme 2).

When there is no excess hydrogen in the hydrogenoxygen system and the homomolecular dimer $\mathrm{O}_{4}$ [42$45,63,64]$, which exists at low concentrations (depending on the pressure and temperature) in

\footnotetext{
${ }^{10}$ The planar, six-atom, cyclic, hydrogen-bonded dimer $\left(\mathrm{HO}_{2}^{*}\right)_{2}$ was calculated using quantum chemical methods (B3LYP density functional theory) [62]. The hydrogen bond energy is 47.7 and $49.4 \mathrm{~kJ} \mathrm{~mol}^{-1}$ at $298 \mathrm{~K}$ for the triplet and singlet states of the dimer, respectively.
}

equilibrium with $\mathrm{O}_{2}$ [41], can directly capture the $\mathrm{H}^{\circ}$ atom to yield the heteronuclear cluster $\mathrm{HO}_{4}^{\bullet}{ }^{11}$, which is more stable than $\mathrm{O}_{4}$ [41] and cannot abstract a hydrogen atom from the hydrogen molecule, nonchain hydrogen oxidation will occur to give molecular oxidation products via the disproportionation of free radicals.

The low-reactive hydrotetraoxyl radical $\mathrm{HO}_{4}^{\bullet}$ [55], which presumably has a high energy density [42], may be an intermediate in the efficient absorption and conversion of biologically hazardous UV radiation energy the Earth upper atmosphere. The potential energy surface for the atmospheric reaction $\mathrm{HO}^{\circ}+\mathrm{O}_{3}$, in which the adduct $\mathrm{HO}_{4}^{-}\left({ }^{2} A\right)$ was considered as an intermediate, was calculated by the DMBE method [65]. From this standpoint, the following reactions are possible in the upper troposphere, as well as in the lower and middle stratosphere, where most of the ozone layer is situated (altitude of $16-30 \mathrm{~km}$, temperature of $217-227 \mathrm{~K}$, pressure of $1.0 \times 10^{4}-1.2 \times$ $10^{3} \mathrm{~Pa}$ [66]; the corresponding $\Delta H_{298}^{\circ}$ reaction values are given in $\left.\mathrm{kJ} \mathrm{mol}^{-1}[20]\right)$ :

$\mathrm{H}_{2} \mathrm{O}$ (vapor) $+h v \rightarrow \mathrm{H}^{\circ}+\mathrm{HO}^{\circ}[66]$

$\mathrm{HO}^{\circ}+\mathrm{O}_{3} \rightarrow \mathrm{HO}_{4}^{\circ}[53,55,65], \quad \Delta H_{298}^{\circ}=-59.5 ;(9)$

$$
\begin{aligned}
\mathrm{HO}_{4}^{\circ} & \rightarrow \mathrm{HO}_{2}^{+}+\mathrm{O}_{2}\left(\mathrm{X}^{3} \Sigma_{\mathrm{g}}^{-}\right)[55,65], \quad \Delta H_{298}^{\circ}=-110.0 \\
& \left(\text { or } \mathrm{HO}_{2}^{-}+\mathrm{O}_{2}\left(a^{1} \Delta_{\mathrm{g}}\right), \quad \Delta H_{298}^{\circ}=-15.7 . \quad\right. \text { (10) }
\end{aligned}
$$

The $\mathrm{HO}_{4}^{*}$ radical can disappear via disproportionation with a molecule, free radical, or atom in addition to dissociation. Note that emission from $\mathrm{O}_{2}\left(a^{1} \Delta_{\mathrm{g}}\right)$ and $\mathrm{O}_{2}\left(b^{1} \Sigma_{\mathrm{g}}^{+}\right)$is observed at altitudes of 30 80 and $40-130 \mathrm{~km}$, respectively [67].

Staehelin et al. [55] pointed out that, in natural systems in which the concentrations of intermediates are often very low, kinetic chains in chain reactions can be very long in the absence of scavengers since the rates of the chain termination reactions decrease with decreasing concentrations of the intermediates according to a quadratic law, whereas the rates of the chain propagation reactions decrease according to a linear law.

\footnotetext{
${ }^{11}$ It is impossible to make a sharp distinction between the two-step bimolecular interaction of three species via the equilibrium formation of the labile intermediate $\mathrm{O}_{4}$ and the elementary termolecular reaction $\mathrm{O}_{2}+\mathrm{O}_{2}+\mathrm{H}^{\circ} \rightarrow$ $\mathrm{HO}_{4}^{\circ}$
} 
The kinetic description of the noncatalytic oxidation of hydrogen, including in an inert medium [60], in terms of the simplified scheme of free-radical nonbranchedchain reactions (Scheme 2), which considers only quadratic-law chain termination and ignores the surface effects [12], at moderate temperatures and pressures, in the absence of transitions to unsteady-state critical regimes, and at a substantial excess of the hydrogen concentration over the oxygen concentration was obtained by means of quasi-steady-state treatment, as in the previous studies on the kinetics of the branchedchain free-radical oxidation of hydrogen [47], even though the applicability of this method in the latter case under unsteady states conditions was insufficiently substantiated. The method was used with the following condition $^{12}: k_{6}=\sqrt{2 k_{5} 2 k_{7}}[1,8]$.

The equation $V_{3}\left(\mathrm{H}_{2} \mathrm{O}_{2} ; \mathrm{H}_{2} \mathrm{O}\right)=V_{3}\left(\mathrm{H}_{2} \mathrm{O}\right)$ for the rate of the chain formation of hydrogen peroxide in the reaction (3) and water in reactions 3 and $3^{\prime}$ with $V_{3,3}\left(\mathrm{H}_{2} \mathrm{O}\right)=2 V_{3}$ is identical to Eq. $(1,1 \mathrm{a})$ with the corresponding analytical expression for $k_{2}$ provided that $\beta=0$ everywhere. The ratio of the rates of the competing reactions is $V_{3} / V_{4}=\alpha / / x$, and the chain length is $v=V_{3} / V_{1}$. The equations for the rates of nonchain formation of hydrogen peroxide and water via reactions 6 and 7 - quadratic-law chain termination are identical to Eqs. (4) and (5) assuming that $\beta=0$. In these equations, $I$ and $x$ are the initial molar concentrations of hydrogen and oxygen $(I>>x), I_{m}$ and $x_{m}$ are the respective concentrations at the maximum point of the function, $V_{1}$ is the rate of initiation (reaction 1), $\alpha=k_{3} / k_{4}$, the rate constant $k_{2}=\alpha l_{m} \sqrt{2 k_{5} V_{1}} / x_{m}^{2}$ is derived from the condition $\partial V_{3} / \partial x=0$, and $2 k_{5}$ is the rate constant of reaction 5 (hydrogen atom recombination), which is considered as bimolecular within the given approximation.

The rate constant $2 k_{5}$ in the case of the pulsed radiolysis of ammonia-oxygen ( + argon) gaseous mixtures at a total pressure of $10^{5} \mathrm{~Pa}$ and a temperature of $349 \mathrm{~K}$ was calculated to be $1.6 \times 10^{8}$ $\mathrm{dm}^{3} \mathrm{~mol}^{-1} \mathrm{~s}^{-1}$ [36] (a similar value of this constant for the gas phase was reported in an earlier publication [68]). Pagsberg et al. [36] found that the dependence of the yield of the intermediate $\mathrm{HO}^{\circ}$ on the oxygen concentration has a maximum close to $5 \times 10^{-4} \mathrm{~mol}$

\footnotetext{
${ }^{12}$ For example, the ratio of the rate constants of the bimolecular disproportionation and dimerization of free radicals at room temperature is $k\left(\mathrm{HO}^{\circ}+\mathrm{HO}_{2}^{\circ}\right) /\left[2 k\left(2 \mathrm{HO}^{\circ}\right) 2 k\left(2 \mathrm{HO}_{2}^{\circ}\right)\right]^{0.5}=2.8$ in the atmosphere [66] and $k\left(\mathrm{H}^{\circ}+\right.$ $\left.\mathrm{HO}^{\circ}\right) /\left[2 k\left(2 \mathrm{H}^{\circ}\right) \times 2 k\left(2 \mathrm{HO}^{\circ}\right)\right]^{0.5}=1.5$ in water [4]. These values that are fairly close to unity.
}

$\mathrm{dm}^{-3}$. In the computer simulation of the process, they considered the strongly exothermic reaction $\mathrm{HO}_{2}^{+}+$ $\mathrm{NH}_{3} \rightarrow \mathrm{H}_{2} \mathrm{O}+{ }^{-} \mathrm{NHOH}$, which is similar to reaction 3 in Scheme 2, whereas the competing reaction 4 was not taken into account.

The rate of the nonbranched-chain free-radical oxidation of hydrogen is a complex function of the rates of formation and disappearance of $\mathrm{H}^{\circ}$ atoms and $\mathrm{HO}_{4}^{\circ}$ radicals: $V_{1}+V_{3,3^{\prime}}-V_{4}-V_{5}+V_{7}$. Unlike the dependences of the rates $V_{4}\left(V_{4} \leq V_{1}\right), V_{5}$ and $V_{7}$, the dependences of the rates $V_{2}, V_{3,3}$, and $2 V_{6}$ on the oxygen concentration $x$ show a maximum.

Equation (1) with $\beta=0$ under the conditions $k_{2} x^{2}>>$ $(\alpha l+x) \sqrt{2 k_{5} V_{1}}$ and $k_{2} x^{2}<(\alpha l+x) \sqrt{2 k_{5} V_{1}}, \alpha l>>x$, corresponding to the descending and ascending branches of the curve with a maximum, can be transformed into simple equations which allow preliminary to estimate the parameters $\alpha$ and $k_{2}$ and express inversely (see Eq. (6)) and directly proportional functions of concentration $x$ :

$$
V_{3}=\sqrt{V_{1}} k_{2} x / \sqrt{2 k_{5}} .
$$

In the case of nonchain hydrogen oxidation via the above addition reaction $\left(\mathrm{H}^{\circ}+\mathrm{O}_{4} \stackrel{k_{\text {add }}}{\longrightarrow} \mathrm{HO}_{4}^{\circ}\right)$, the formation rates of the molecular oxidation products in reactions 6 and 7 (Scheme 2, $k_{2}=k_{3}=k_{4}=0$ ) are defined by modified Eqs. (4) and (5) in which $\beta=0,(\alpha)$ $+x$ ) is replaced with 1 , and $k_{2}$ is replaced with $k_{a d d} K_{e q}$ $\left(k_{\text {add }} K_{\text {eq }}\right.$ is the effective rate constant of $\mathrm{H}^{*}$ addition to the $\mathrm{O}_{4}$ dimer, $K_{e q}=k / k^{\prime}$ is the equilibrium constant of the reversible reaction $2 \mathrm{O}_{2} \underset{k^{\prime}}{\stackrel{k}{\Leftrightarrow}} \mathrm{O}_{4}$ with $\left.k^{\prime}>>k_{a d d}\left[\mathrm{H}^{\circ}\right]\right)$. The formation rates of the stable products of nonchain oxidation $\left(k_{3}=0\right)$, provided that either reactions 2 and 4 or reaction 2 alone $\left(k_{4}=0\right)$ occurs (Scheme 2; in the latter case, reactions 6 and 7 involve the $\mathrm{HO}_{2}^{*}$ radical rather than $\mathrm{HO}_{4}^{-}$), are given by modified Eqs. (4) and (5) with $\beta=0,(\alpha I+x)$ replaced with 1 , and $x^{2}$ replaced with $x$.

Note that, if in Scheme 2 chain initiation via reaction 1 is due to the interaction between molecular hydrogen and molecular oxygen yielding the hydroxyl radical $\mathrm{HO}^{\circ}$ instead of $\mathrm{H}^{*}$ atoms and if this radical reacts with an oxygen molecule (reaction 4) to form the hydrotrioxyl radical $\mathrm{HO}_{3}^{*}$ (which was obtained in the gas phase by neutralization reionization (NR) mass spectrometry [56] and has a lifetime of $>10^{-6} \mathrm{~s}$ at $298 \mathrm{~K}$ ) and chain termination takes place via reactions 5-7 involving the $\mathrm{HO}$ and $\mathrm{HO}_{3}^{\circ}$ radicals instead of $\mathrm{H}^{\circ}$ and $\mathrm{HO}_{4}^{*}$, respectively, the expressions for the water chain formation rates derived in the same way will appear as 
a rational function of the oxygen concentration $x$ without a maximum: $V_{3^{\prime}}\left(\mathrm{H}_{2} \mathrm{O}\right)=V_{1} k_{3} l /\left(k_{4} x+\sqrt{2 k_{5} V_{1}}\right)$.

Curve 2 in Figure 1 describes, in terms of the overall equation $V_{3,7}=V_{1} x\left(\alpha l f_{m}+x^{3}\right) / f_{m}^{2}$ for the rates of reactions 3 and 7 (which was derived from Eqs. (1a) and (5), respectively, with $\beta=0$, Eq. (5) in the form [69] of

$$
V_{7}=V_{1} x^{4} / f_{m}^{2}
$$

in which $k_{2}$ is replaced with its analytical expression $\alpha l_{m} \sqrt{2 k_{5} V_{1}} / x_{m}^{2}$ derived from Eq. (1) with $\beta=0$ everywhere), the dependence of the hydrogen peroxide formation rate (minus the rate $V_{\mathrm{H}_{2} \mathrm{O}_{2}}=5.19 \times 10^{-8} \mathrm{~mol}$ $\mathrm{dm}^{-3} \mathrm{~s}^{-1}$ of the primary formation of hydrogen peroxide after completion of the reactions in spurs) on the initial concentration of dissolved oxygen during the $\gamma$ radiolysis of water saturated with hydrogen $\left(7 \times 10^{-4}\right.$ $\mathrm{mol} \mathrm{dm}^{-3}$ ) at $296 \mathrm{~K}$ [34]. These data were calculated in the present work from the initial slopes of hydrogen peroxide buildup versus dose curves for a ${ }^{60} \mathrm{Co} \gamma$ radiation dose rate of $P=0.67 \mathrm{~Gy} \mathrm{~s}^{-1}$ and absorbed doses of $D \cong 22.5-304.0$ Gy. The following values of the primary radiation-chemical yield $\mathrm{G}$ (species per 100 $\mathrm{eV}$ of energy absorbed) for water $\gamma$-radiolysis products in the bulk of solution at $\mathrm{pH} 4-9$ and room temperature were used (taking into account that $V=G P$ and $V_{1}=$ $G_{\mathrm{H}} P$ ): $G_{\mathrm{H}_{2} \mathrm{O}_{2}}=0.75$ and $G_{\mathrm{H}}=0.6$ (initiation yield) [4]; $V_{1}$ $=4.15 \times 10^{-8} \mathrm{~mol} \mathrm{dm}^{-3} \mathrm{~s}^{-1} ; 2 k_{5}=2.0 \times 10^{10} \mathrm{dm}^{3} \mathrm{~mol}^{-1}$ $\mathrm{s}^{-1}$ [4]. As can be seen from Figure 1, the best description of the data with an increase in the oxygen concentration in water is attained when the rate $V_{7}$ of the formation of hydrogen peroxide via the nonchain mechanism in the chain termination reaction 7 (curve 1, $\left.\alpha=(8.5 \pm 2) \times 10^{-2}\right)$ is taken into account in addition to the rate $V_{3}$ of the chain formation of this product via the propagation reaction 3 (dashed curve 2, $\alpha=0.11 \pm$ 0.026). The rate constant of addition reaction 2 determined from $\alpha$ is substantially underestimated: $k_{2}=$ $1.34 \times 10^{7}$ (vs $2.0 \times 10^{10}$ [4]) $\mathrm{dm}^{3} \mathrm{~mol}^{-1} \mathrm{~s}^{-1}$. The difference can be due to the fact that the radiationchemical specifics of the process were not considered in the kinetic description of the experimental data. These include oxygen consumption via reactions that are not involved in the hydrogen oxidation Scheme 2 and reverse reactions resulting in the decomposition of hydrogen peroxide by intermediate products of water radiolysis $\left(\mathrm{e}_{\mathrm{aq}}^{-}, \mathrm{H}^{*}, \mathrm{HO}^{\circ}\right)$, with the major role played by the hydrated electron [4].

\section{CONCLUSIONS}

The above data concerning the competition kinetics of the nonbranched-chain addition of hydrocarbon free radicals and hydrogen atoms to the multiple bonds of the oxygen molecules make it possible to describe, using rate equations (1a) and (5a), obtained by quasisteady-state treatment, the peaking experimental dependences of the formation rates of molecular $1: 1$ adducts (in this case the $0-\mathrm{CH}_{3} \mathrm{C}_{6} \mathrm{H}_{4} \mathrm{CH}_{2} \mathrm{O}_{2} \mathrm{H}$ or $\mathrm{H}_{2} \mathrm{O}_{2}$ ) on the initial concentration of the oxygen over the entire range of its variation in binary systems (Figure 1). In such reaction systems consisting of saturated and unsaturated components $[1,13-15,27,28,37,38,69$ 72], the unsaturated compound (in this case the $\mathrm{O}_{2}$ ) is both a reactant and an autoinhibitor, specifically, a source of low-reactive free radicals (in this case the $\mathrm{RO}_{4}^{-}$or $\mathrm{HO}_{4}^{-}$radicals) shortening kinetic chains. The progressive inhibition of the nonbranched-chain processes, which takes place as the concentration of the unsaturated compound is raised (after the maximum process rate is reached), can be an element of the self-regulation of the natural processes that returns them to the stable steady state.

Using mechanism of the nonbranched-chain freeradical hydrogen oxidation considered here, it has been demonstrated that, in the Earth's upper atmosphere, the decomposition of $\mathrm{O}_{3}$ in its reaction with the $\mathrm{HO}^{\circ}$ radical can occur via the addition of the latter to the ozone molecule, yielding the $\mathrm{HO}_{4}^{*}$ radical, which is capable of efficiently absorbing UV radiation [55].

\section{REFERENCES}

[1] Silaev MM, Bugaenko LT. Mathematical Simulation of the Kinetics of Radiation Induced Hydroxyalkylation of Aliphatic Saturated Alcohols. Radiat Phys Chem 1992; 40(1): 1-10.

[2] Vereshchinskii IV, Pikaev AK. Vvedenie $v$ radiatsionnuyu khimiyu (Introduction to Radiation Chemistry), Spitsyn VI, Ed. Akademiya Nauk SSSR, Moscow 1963; pp. 190.

[3] Silaev MM. Applied Aspects of the $\mathrm{Y}$-Radiolysis of $\mathrm{C}_{1}-\mathrm{C}_{4}$ Alcohols and Binary Mixtures on Their Basis. Khimiya Vysokikh Energii 2002; 36(2): 97-101; English Translation in: High Energy Chemistry 2002; 36(2): 70-74.

\section{http://dx.doi.org/10.1023/A:1014650726821}

[4] Pikaev AK. Sovremennaya radiatsionnaya khimiya. Radioliz gazov i zhidkostei (Modern Radiation Chemistry: Radiolysis of Gases and Liquids). Nauka, Moscow 1986.

[5] Emanuel NM, Denisov ET, Maizus ZK. Tsepnye reaktsii okisleniya uglevodorodov $v$ zhidkoi faze. (Chain Oxidation Reactions of Hydrocarbons in the Liquid Phase). Nauka, Moscow 1965.

[6] Benson SW. Thermochemical Kinetics: Methods for the Estimation of Thermochemical Data and Rate Parameters. $2^{\text {nd }}$ ed. Wiley, New York 1976.

[7] Walling Ch. Free Radicals in Solution. Wiley, New York 1956.

[8] Bateman L. Olefin Oxidation. Quarterly Reviews 1954; 8(2): 147-67.

[9] Shtern VYa. Mekhanizm okisleniya uglevodorodov $v$ gazovoi faze (Mechanism of the Gas-Phase Oxidation of Hydrocarbons). Akademiya Nauk SSSR, Moscow 1960. 
[10] Bäckström HLJ. Der Kettenmechanismus bei der Autoxydation von Aldehyden", Zeitschrift für physikalische Chemie (B). 1934; 25(1-2): 99-121.

[11] Aliev AA. Saraeva VV. Isomerization of Peroxy Radicals Resulting from the Radiation-Induced Oxidation of o-Xylene. Vestnik Moskovskogo Universiteta, Ser. 2: Khimiya 1983; 34(4): 371-74.

[12] Badin EJ. The Reaction between Atomic Hydrogen and Molecular Oxygen at Low Pressures. Surface Effects. J Am Chem Soc 1948; 70(11): 3651-55.

http://dx.doi.org/10.1021/ja01191a032

[13] Silaev MM. A New Competitive Kinetic Model of Radical Chain Oxidation: Oxygen as an Autoinhibitor. Biofizika 2001; 46(2): 203-209, English Translation in: Biophysics 2001; 46(2): 202-207.

[14] Silaev MM. Simulation of the Initiated Addition of Hydrocarbon Free Radicals and Hydrogen Atoms to Oxygen via a Nonbranched Chain Mechanism. Teoreticheskie Osnovy Khimicheskoi Tekhnologii 2007; 41(6): 634-42. English Translation in: Theoretical Foundation of Chemical Engineering 2007; 41(6): 831-38.

http://dx.doi.org/10.1134/S0040579507060073

[15] Silaev MM, Bugaenko LT. Kinetics of the Addition of $\alpha-$ Hydroxyalkyl Radicals to 2-Propen-1-ol and Formaldehyde. Kinet Katal 1994; 35(4): 509-13.

[16] Gurvich LV, Karachevtsev GV, Kondrat'ev VN, Lebedev YuA, Medvedev VA, Potapov VK, Khodeev YuS. Energii razryva khimicheskikh svyazei. Potentsialy ionizatsii i srodstvo k elektronu. (Bond Dissociation Energies, Ionization Potentials, and Electron Affinity). Kondrat'ev VN, Ed. Nauka, Moscow 1974.

[17] Orlov YuD, Lebedev YuA, Saifullin ISh. Termokhimiya organicheskikh svobodnykh radikalov (Thermochemistry of Organic Free Radicals). Kutepov AM, Ed. Nauka, Moscow 2001.

[18] Pedley JB, Naylor RD, Kirby SP. Thermochemical Data of Organic Compounds. $2^{\text {nd }}$ ed. Chapman \& Hall, London 1986.

[19] Buchachenko AL. Kompleksy radikalov i molekulyarnogo kisloroda $s$ organicheskimi molekulami. (Complexes of Radicals and Dioxygen with Organic Molecules). Beletskaya IP, Ed. Nauka, Moscow 1984.

[20] Francisco JS, Williams IH. The Thermochemistry of Polyoxides and Polyoxy Radicals. Int J Chem Kinetics 1988; 20(6): 455-66.

http://dx.doi.org/10.1002/kin.550200605

[21] Kokorev VN, Vyshinskii NN, Maslennikov VP, Abronin IA, Zhidomirov GM, Aleksandrov YuA. Electronic Structure and Chemical Reactions of Peroxides: I. MINDO/3 Calculation of the Geometry and Enthalpy of Formation of the Ground States of Organic and Organoelement Peroxides. Zhurnal Strukturnoi Khimii 1981; 22(4): 9-15.

[22] Dmitruk AF, Lobanov VV, Kholoimova LI. Role of Tetroxide Conformation in the Mechanism of Peroxy Radical Recombination. Teoreticheskaya i Eksperimental'naya Khimiya 1986; 22(3): 363-66.

[23] Belyakov VA, Vasil'ev RF, Ivanova NM, Minaev BF, Osyaeva OV, Fedorova GF. Electronic Model of the Excitation of Chemiluminescence in the Oxidation of Organic Compounds. Izvestiya Akademii Nauk SSSR, Ser.: Fizika 1987; 51(3): 540-47.

[24] Ase P, Bock W, Snelson A. Alkylperoxy and Alkyl Radicals. 1. Infrared Spectra of $\mathrm{CH}_{3} \mathrm{O}_{2}$ and $\mathrm{CH}_{3} \mathrm{O}_{4} \mathrm{CH}_{3}$ and the Ultraviolet Photolysis of $\mathrm{CH}_{3} \mathrm{O}_{2}$ in Argon + Oxygen Matrices. J Phys Chem 1986; 90(10): 2099-109. http://dx.doi.org/10.1021//100401a024

[25] Pimentel GC, McClellan AL. The Hydrogen Bond. Pauling L, Ed. Freeman, San Francisco 1960; p. 200.
[26] Russell GA. Deuterium-Isotope Effects in the Autooxidation of Aralkyl Hydrocarbons: Mechanism of the Interaction of Peroxy Radicals. J Am Chem Soc 1957; 79(14): 3871-77. http://dx.doi.org/10.1021/ja01571a068

[27] Silaev MM. The Competition Kinetics of Nonbranched Chain Processes of Free-Radical Addition to Double Bonds of Molecules with the Formation of 1:1 Adducts and the Inhibition by the Substrate. Oxidation Commun 1999; 22(2): 159-70.

[28] Silaev MM. The Competition Kinetics of Radical-Chain Addition. Zhurnal Fizicheskoi Khimii 1999; 73(7): 1180-84, English Translation in: Russian Journal of Physical Chemistry 1999; 73(7): 1050-1054.

[29] Darmanyan AP, Gregory DD, Guo Y, Jenks WS, Burel L, Eloy D, Jardon P. Quenching of Singlet Oxygen by Oxygenand Sulfur-Centered Radicals: Evidence for Energy Transfer to Peroxy Radicals in Solution. J Am Chem Soc 1998; 120(2): 396-403.

http://dx.doi.org/10.1021/ja9730831

[30] Kanofsky JR. Singlet Oxygen Production from the Reactions of Alkylperoxy Radicals. Evidence from 1268-nm Chemiluminescence. J Org Chem 1986; 51(17): 3386-88. http://dx.doi.org/10.1021/j000367a032

[31] Semenov NN. Tsepnye reaktsii. (Chain Reactions). Goskhimtekhizdat, Leningrad 1934; pp. 241, 203.

[32] Reznikovskii M, Tarasova Z, Dogadkin B. Oxygen Solubility in Some Organic Liquids. Zhurnal Obshchei Khimii 1950; 20(1): 63-67.

[33] Howard JA, Ingold KU. Absolute Rate Constants for Hydrocarbon Autooxidation. VI. Alkyl Aromatic and Olefinic Hydrocarbons. Can J Chem 1967; 45(8): 793-802. http://dx.doi.org/10.1139/v67-132

[34] Barr NF, Allen AO. Hydrogen Atoms in the Radiolysis of Water. J Phys Chem 1959; 63(6): 928-31. http://dx.doi.org/10.1021/j150576a037

[35] Smith HA, Napravnik A. Photochemical Oxidation of Hydrogen. J Am Chem Soc 1940; 62(1): 385-93.

http://dx.doi.org/10.1021/ja01859a043

[36] Pagsberg PB, Eriksen J, Christensen HC. Pulse Radiolysis of Gaseous Ammonia-Oxygen Mixtures. J Phys Chem 1979; 83(5): 582-90. http://dx.doi.org/10.1021/j100468a006

[37] Silaev MM. Competitive Mechanism of the Non-branched Radical Chain Oxidation of Hydrogen Involvingthe Free Cyclohydrotetraoxyl Radical $\left[\mathrm{OO}^{\circ \cdots} \mathrm{H}^{\cdots} \mathrm{OO}\right]$; , which Inhibits the Chain Process. Khimiya Vysokikh Energii 2003; 37(1): 27-32, English Translation in: High Energy Chemistry 2003; 37(1): 24-28.

[38] Silaev MM. Simulation of Initiated Nonbranched Chain Oxidation of Hydrogen: Oxygen as an Autoinhibitor. Khimiya Vysokich Energii 2008; 42(2): 124-29, English Translation in: High Energy Chemistry 2008; 42(1): 95-100. http://dx.doi.org/10.1134/S0018143908020069

[39] McKay DJ, Wright JS. How Long Can You Make an Oxygen Chain? J Am Chem Soc 1998; 120(5): 1003-13. http://dx.doi.org/10.1021/ja971534b

[40] Lipikhin NP. Dimers, Clusters, and Cluster lons of Oxygen in the Gas Phase. Uspekhi Khimii 1975; 44(8): 366-76. http://dx.doi.org/10.1070/RC1975v044n08ABEH002366

[41] Razumovskii SD. Kislorod - elementarnye formy i svoistva. (Oxygen: Elementary Forms and Properties). Khimiya, Moscow 1979.

[42] Dunn KM, Scuceria GE, Schaefer HF III. The infrared spectrum of cyclotetraoxygen, $\mathrm{O}_{4}$ : a theoretical investigation employing the single and double excitation coupled cluster method. J Chem Phys 1990; 92(10): 6077-80. http://dx.doi.org/10.1063/1.458380 
[43] Brown L, Vaida V. Photoreactivity of Oxygen Dimers in the Ultraviolet. J Phys Chem 1996; 100(19): 7849-53. http://dx.doi.org/10.1021/jp9526713

[44] Aquilanti V, Ascenzi D, Bartolomei M, Cappelletti D, Cavalli S, de Castro-Vitores M, Pirani F. Molecular Beam Scattering of Aligned Oxygen Molecules. The Nature of the Bond in the $\mathrm{O}_{2}-\mathrm{O}_{2}$ Dimer. J Am Chem Soc 1999; 121(46): 10794-80. http://dx.doi.org/10.1021/ja9917215

[45] Cacace F, de Petris G, Troiani A. Experimental Detection of Tetraoxygen. Angew Chem Intern Ed (in English) 2001; 40(21): 4062-65.

http://dx.doi.org/10.1002/1521-

3773(20011105)40:21<4062::AID-ANIE4062>3.0.CO;2-X

[46] Taylor HS. Photosensitisation and the Mechanism of Chemical Reactions. Trans Faraday Soc 1926; 21(63(3)): 560-68.

http://dx.doi.org/10.1039/tf9262100560

[47] Nalbandyan AB, Voevodskii VV. Mekhanizm okisleniya i goreniya vodoroda. (Mechanism of Hydrogen Oxidation and Combustion). Kondrat'ev VN, Ed. Akad. Nauk SSSR, Moscow 1949.

[48] Foner SN, Hudson RL. Mass spectrometry of the $\mathrm{HO}_{2}$ free radical. J Chem Phys 1962; 36(10): 2681. http://dx.doi.org/10.1063/1.1732352

[49] Hochanadel CJ, Ghormley JA, Ogren PJ. Absorption Spectrum and Reaction Kinetics of the $\mathrm{HO}_{2}$ Radical in the Gas Phase. J Chem Phys 1972; 56(9): 4426-32. http://dx.doi.org/10.1063/1.1677885

[50] Lightfoot PD, Veyret $\mathrm{B}$, Lesclaux R. Flash Photolysis Study of the $\mathrm{CH}_{3} \mathrm{O}_{2}+\mathrm{HO}_{2}$ Reaction between 248 and $573 \mathrm{~K}$. J Phys Chem 1990; 94(2): 708-14. http://dx.doi.org/10.1021/j100365a036

[51] Smith P. The $\mathrm{HO}_{3}$ and $\mathrm{HO}_{4}$ Free Radicals. Chem Ind 1954; 42: 1299-300.

[52] Robertson AJB. A Mass Spectral Search for $\mathrm{H}_{2} \mathrm{O}_{4}$ and $\mathrm{HO}_{4}$ in a Gaseous Mixture Containing $\mathrm{HO}_{2}$ and $\mathrm{O}_{2}$. Chem Ind 1954; 48: 1485 .

[53] Bahnemann D, Hart EJ. Rate Constants of the Reaction of the Hydrated Electron and Hydroxyl Radical with Ozone in Aqueous Solution. J Phys Chem 1982; 86(2): 252-55. http://dx.doi.org/10.1021/j100391a024

[54] Vodorodnaya svyaz': Sbornik statei. (The Hydrogen Bonding: Collection of Articles). Sokolov ND, Ed, Nauka, Moscow 1981.

[55] Staehelin J, Bühler RE, Hoigné J. Ozone Decomposition in Water Studied by Pulse Radiolysis. 2. $\mathrm{OH}$ and $\mathrm{HO}_{4}$ as Chain Intermediates. J Phys Chem 1984; 88(24): 5999-6004. http://dx.doi.org/10.1021/j150668a051

[56] Cacace F, de Petris G, Pepi F, Troiani A. Experimental Detection of Hydrogen Trioxide. Science 1999; 285(5424): 81-82.

http://dx.doi.org/10.1126/science.285.5424.81

[57] Bühler RF, Staehelin J, Hoigné J. Ozone Decomposition in Water Studied by Pulse Radiolysis. 1. $\mathrm{HO}_{2} / \mathrm{O}_{2}{ }^{-}$and $\mathrm{HO}_{3} / \mathrm{O}_{3}{ }^{-}$ as Intermediates. J Phys Chem 1984; 88(12): 2560-64. http://dx.doi.org/10.1021/j150656a026

[58] Trushkov IV, Silaev MM, Chuvylkin ND. Acyclic and Cyclic Forms of the Radicals $\mathrm{HO}_{4}^{\bullet}, \mathrm{CH}_{3} \mathrm{O}_{4}^{\bullet}$, and $\mathrm{C}_{2} \mathrm{H}_{5} \mathrm{O}_{4}^{\bullet}$ : Ab Initio
Quantum Chemical Calculations. Izvestiya Akademii Nauk, Ser.: Khimiya 2009; 3: 479-82, English Translation in: Russian Chemical Bulletin, International Edition 2009; 58(3): 489-92.

[59] Mansergas A, Anglada JM, Olivella S, Ruiz-López MF. On the Nature of the Unusually Long $\mathrm{OO}$ Bond in $\mathrm{HO}_{3}$ and $\mathrm{HO}_{4}$ Radicals. Phys Chem Chem Phys 2007; 9(44): 5865-73. http://dx.doi.org/10.1039/b711464h

[60] Wong W, Davis DD. A Flash Photolysis Resonance Fluorescence Study of the Reactions of Atomic Hydrogen and Molecular Oxygen: $\mathrm{H}+\mathrm{O}_{2}+\mathrm{M} \rightarrow \mathrm{HO}_{2}+\mathrm{M}$. Int $\mathrm{J}$ Chem Kinetics 1974; 6(3): 401-16 http://dx.doi.org/10.1002/kin.550060310

[61] Yagodovskaya TV, Nekrasov LI. Zh Fiz Khim 1977; 51(10): 2434-45.

[62] Xu X, Muller RP, Goddard WA III. The Gas Phase Reaction of Singlet Dioxygen with Water: a Water-Catalyzed Mechanism. Proc Natl Acad Sci USA 2002; 99(6): 3376-81. http://dx.doi.org/10.1073/pnas.052710099

[63] Seidl ET, Schaefer HF III. Is There a Transition State for the Unimolecular Dissociation of Cyclotetraoxygen $\left(\mathrm{O}_{4}\right)$ ? J Chem Phys 1992; 96(2): 1176-82.

http://dx.doi.org/10.1063/1.462205

[64] Hernández-Lamoneda R, Ramírez-Solís A. Reactivity and Electronic States of $\mathrm{O}_{4}$ along Minimum Energy Paths. J Chem Phys 2000; 113(10): 4139-45. http://dx.doi.org/10.1063/1.1288370

[65] Varandas AJC, Zhang L. Test Studies on the Potential Energy Surface and Rate Constant for the $\mathrm{OH}+\mathrm{O}_{3}$ Atmospheric Reaction. Chem Phys Lett 2000; 331(5-6): 47482

http://dx.doi.org/10.1016/S0009-2614(00)01222-7

[66] Atmosfera. Spravochnik (Atmosphere: A Handbook), Gidrometeoizdat, Leningrad 1991.

[67] Okabe H. Photochemistry of Small Molecules. Wiley, New York 1978.

[68] Boyd AW, Willis C, Miller OA. A Re-examination of the Yields in the High Dose Rate Radiolysis of Gaseous Ammonia. Can J Chem 1971; 49(13): 2283-89. http://dx.doi.org/10.1139/v71-369

[69] Silaev MM. Competition Mechanism of Substrate-Inhibited Radical Chain Addition to Double Bond. Neftekhimiya 2000; 40(1): 33-40, English Translation in: Petroleum Chemistry 2000; 40(1): 29-35.

[70] Silaev MM. Competition Kinetics of Nonbranched Chain Processes of Free Radical Addition to the $\mathrm{C}=\mathrm{C}, \mathrm{C}=\mathrm{O}$, and $\mathrm{O}=\mathrm{O}$ Double Bonds of Molecules. Neftekhimiya 2003; 43(4): 302-307, English Translation in: Petroleum Chemistry, 2003; 43(4): pp. 258-73.

[71] Silaev MM. Low-reactive Free Radicals Inhibiting Nonbranched Chain Processes of Addition. Biofizika 2005; 50(4): 585-600, English Translation in: Biophysics 2005; 50(4): 511-24.

[72] Silaev M. Reactions of the Free-Radical Addition: Heat Effects, Competition Kinetics of the Nonbranched-Chain Processes, Inhibition by Low-Reactive Radicals. Res Bulle Aust Instit High Energetic Mater 2011; 2: 122-58. 